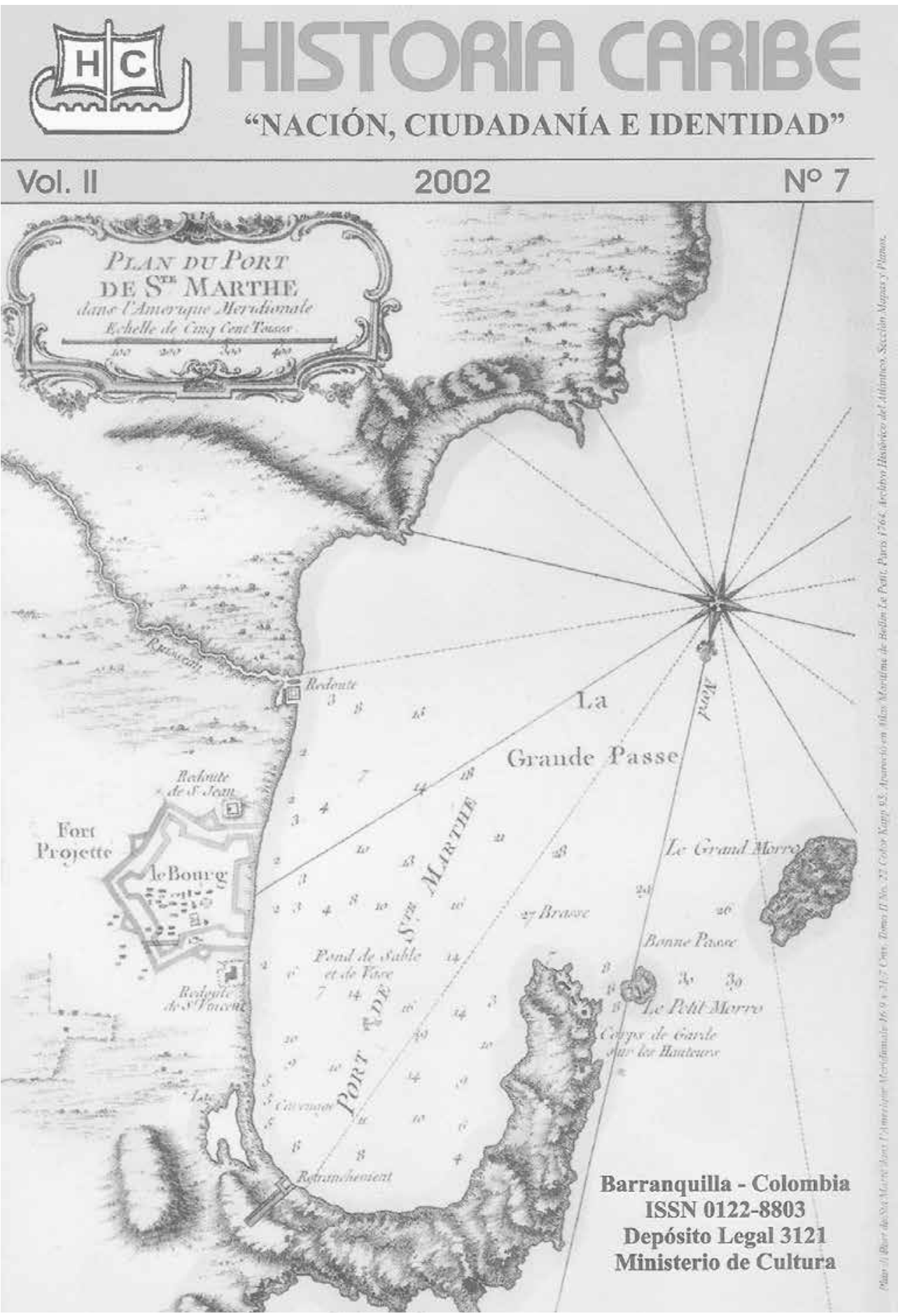




\title{
Entre fulgores de ángeles y máculas de tizne: energía, metabolismo y degradación ecológica en el Valle de Puebla-Tlaxcala, 1530-1820\%
}

\begin{abstract}
JOSÉ JUAN JuÁREZ FlORES
Profesor de Historia de la Universidad Autónoma de Tlaxcala (México). Correo electrónico: macaur3@ yahoo.com.mx. El autor es Doctor y Maestro en Historia de la Universidad Autónoma Metropolitana, Unidad Iztapalapa (México), también es Licenciado en Historia de la Benemérita Universidad Autónoma de Puebla (México). Entre sus publicaciones recientes tenemos: "Besieged Forests at Century's End: Industry, Speculation, and Dispossession in Tlaxcala's La Malintzin Woodlands, 1860-1910”, en A Land Between Waters: Environmental Histories of Modern Mexico, eds. Christopher A. Boyer (The University of Arizona Press, 2012) y "Agua, agricultura e industria: las transformaciones en el paisaje lacustre de Tlaxcala, 1850-1900", en La Revolución mexicana en la provincia. Problemas comunes, variantes locales, eds. Juan Uvaldo Estrada Ramos, Elizabeth Jaime Espinosa, Jesús Barbosa Ramírez, José Juan Juárez Flores (México: Universidad Autónoma de Tlaxcala, 2012). Entre sus líneas de investigación tenemos los temas sobre historia económica, agraria, fiscal y ecológica de los procesos urbanos y de los pueblos de indios de la región de Puebla-Tlaxcala durante la Colonia y el siglo XIX.
\end{abstract}

Recibido: 25 de julio de 2014

Aprobado: 11 de septiembre de 2014

Modificado: 10 de octubre de 2014

Artículo de investigación e innovación

DOI: http://dx.doi.org/10.15648/hc.26.2015.7

\footnotetext{
* Este artículo forma parte del proyecto "Malintzin Matlalcuéyetl. Recursos naturales, conflictividad social y la desarticulación ambiental de un entorno ecológico en el desarrollo de los procesos urbanos y sociales del valle Puebla-Tlaxcala, circa 1500-1900", con financiación solidaria.

Esta publicación está bajo una licencia Creative Commons Reconocimiento-Compartir Igual 3.0
} 
Entre fulgores de ángeles y máculas de tizne: energía, metabolismo y degradación ecológica en el Valle de Puebla-Tlaxcala, 1530-1820

\title{
Resumen
}

En este trabajo se analiza y explica la centralidad que han ocupado los recursos naturales en los procesos de crecimiento y transformación como lo han sido los de los espacios urbanos, lo mismo que en las formas de generación de insustentabilidad. A partir de su funcionalidad energética y de infraestructura, se muestra la importancia de la madera para el metabolismo social de la ciudad de Puebla, la segunda en calidad de la Nueva España; la conflictividad social acarreada con los aprovechamientos; beneficios e intereses establecidos sobre el recurso y el impacto en la configuración de una tendencia secular a la descomposición de la articulación ambiental.

Palabras clave: Flujos de energía, metabolismo social, insustentabilidad, conflictividad.

\section{Between angels radiance and grime macules: energy, metabolism and ecologi- cal degradation in the Puebla-Tlaxcala Valley, 1530-1820}

\begin{abstract}
This paper discusses and explains the centrality that has been occupied by natural resources in processes of growth and transformation as they were those of urban spaces and forms of unsustainability generation. From its energy functionality and infrastructure, it is shown the importance of wood for the social metabolism of the city of Puebla, the second in quality in the new Spain; the social conflict carried with the uses, benefits and interests established on the resource and the impact on the configuration of a secular trend in the decomposition of the environmental joint.
\end{abstract}

Key words: Flows of energy, social metabolism, conflicts, unsustainability

Entre o fulgor de anjos e manchas de fuligem: energia, metabolismo e degradação ecológica no Vale do Puebla-Tlaxcala, 1530-1820

\section{Resumo}

Neste trabalho se analisa e explica a centralidade que ocuparam os recursos naturais nos procesos de crescimento e transformação, assim como os espaços urbanos e nas formas de geração de insustentabilidade. A partir da sua funcionalidade energética e de infra-estrutura, se mostra a importancia da madeira para o metabolismo social da cidade 
de Puebla, a segunda em qualidade da Nova Espanha; A conflitualidade social com a exploração, benefícios e interesses adquiridos sobre o uso e impacto na formação de uma tendência secular à decomposição da articulação ambiental.

Palavras-chave: Fluxos de energia, metabolismo social, a insustentabilidade, conflitividad.

\section{Entre lueurs d'anges et taches de suie: énergie, métabolisme et dégradation écologique dans la Vallée de Puebla-Tlaxcala, 1530-1820}

\section{Résumé}

Ce travail analyse et explique la centralité qu'ont eue les ressources naturelles dans les processus de croissance et transformation comme l'ont été ceux des espaces urbains ainsi que dans la génération d'un développement non soutenable. À partir de leur fonctionnalité énergétique et d'infrastructure, on montre l'importance du bois pour le métabolisme social de la ville de Puebla, la deuxième en qualité de la Nouvelle Espagne; les conflits sociaux entrainnés avec les exploitations; des bénéfices et des intérêts établis sur la ressource et l'impact dans la configuration d'une tendance séculaire à la décomposition de l'articulation environnementale.

Mots-clés: Flux d'energie, métabolisme social, développement non soutenable, conflits

La «sustentabilidad», el «desarrollo sustentable», la «explotación sustentable de los recursos», se han constituido en el referente de un discurso que, ante la conflictividad generada en torno a los bienes naturales, se ha hecho recurrente en todos los ámbitos o escenarios para aludir a formas de crecimiento económico más amigables o en armonía con la naturaleza, al cuidado y la conservación de los recursos naturales, a su escasez o deterioro, pero fundamentalmente se le ha insistido para justificar, desde la promoción de políticas públicas de carácter oficial o de Estado, la intervención y apropiación de bienes que se han tornado estratégicos para colocarlos al aprovechamiento y beneficio de los procesos productivos, industriales y de mercado de las agencias e intereses privados.

Las dimensiones alcanzadas por los desastres ecológicos ocasionados por la explotación minera, los derrames de petróleo, la contaminación de sue- 
los y agua con los desechos residuales e industriales, el calentamiento global, el ecocidio de la flora y la fauna, la precariedad social, las expectativas disminuidas, aunado a la negligencia de las empresas para cumplir normatividades regulatorias, la desidia para asumir las responsabilidades ecológicas y sociales, y más aún, la tolerancia o consentimiento dispensados por las instituciones encargadas supuestamente de regularlas, cuestionan severamente; sin embargo, la sostenibilidad del discurso evidencian más bien la agudización de las contradicciones y conflictos propiciados por la irracionalidad de las teorías y paradigmas que han encauzado este modelo de crecimiento económico.

¿Es posible el «desarrollo sustentable»? La degradación de los paisajes y con ello la pérdida de las funciones ecológicas o ambientales que tiene amenazadas las formas de existencia de vida ha hecho de esta una cuestión central para la historia, no solo para señalar porqué o cómo se ha venido acarreando esta situación comprometedora, sino también para contribuir a esa «nueva ciencia de la sostenibilidad» que reclama la confluencia de todas las formas de saber comprometidas con la sustentabilidad del desarrollo humano ${ }^{1}$. Desde la historia y para la historia, entonces, el conocimiento y la aplicación de experiencias vividas que puedan orientar la toma de decisiones validan no solamente la necesidad de la historia sino también la pertinencia de su utilidad como un «saber del salvamento».

¿Existe o ha existido el «desarrollo sustentable»? En otras palabras, ¿ha habido formas históricas de «sustentabilidad»? Como en todo proceso histórico, es este un referente teórico temporal, relativo, señalado por las circunstancias privativas de un determinado espacio y momento y, por consiguiente, mutable en el tiempo. No se trata de lograr un propósito previamente establecido, sino de conseguirlo porque no se le tenía previsto o porque así lo exigen o imponen las circunstancias ${ }^{2}$. ¿Cómo o por

1 Enric Tello, La historia cuenta: del crecimiento económico al desarrollo humano sostenible (Barcelona: Fundació Nous Horitzons/El Viejo Topo, 2005).

2 La sustentabilidad es un objetivo, no un punto de partida, "no una definición normativa", Manuel González de Molina y Gloria I. Guzmán Casado, Tras los pasos de la insustentabilidad. Agricultura y medioambiente en perspectiva histórica (s. XVIII - Xx) (España: Icaria Editorial, 2006), 17. 
qué, entonces, se genera o acarrea la insustentabilidad? ¿Cuáles han sido los procesos que la han conducido? La degradación territorial constata de manera fehaciente que ha sido a partir de pensar la realización de los procesos decisivos solo como fenómenos económicos o sociales disociados de los físico-biológicos o ambientales. La intervención y artificialización de los ecosistemas ha sido para producir alimentos, obtener materias primas y energía o para construir infraestructuras físicas o materiales; en suma, la relación entre naturaleza y sociedad ha sido imprescindible para el «metabolismo social»; sin embargo, los ecosistemas así manipulados, al interferir y alterar la lógica de su funcionamiento, se vuelven inestables y propensos, bajo determinadas condiciones, a perder su sostenibilidad ${ }^{3}$.

El planteamiento, entonces, es que la insostenibilidad deviene de la realización del metabolismo social que impacta en la modificación y alteración de los ecosistemas. En otras palabras, la realización de los procesos decisivos que marcan la transformación y la dinámica socioeconómica ha sido a partir de la producción, desplazamiento, transformación, consumo y desecho de recursos naturales que, en la forma de su gestión, propician formas de insustentabilidad. Una de las líneas de investigación sugeridas para analizar la forma que asume este proceso interactivo es a partir de la descripción y/o medición de los «flujos de energía y materiales» que precisa el metabolismo de procesos como los agrarios, urbanos o industriales, y las consecuencias resultantes en la «matriz territorial». La expectativa es que el conocimiento generado se pueda aplicar para orientar o encauzar hacia formas de desarrollo económico más sostenibles ${ }^{4}$.

3 Manuel González de Molina, "Condicionamientos ambientales del crecimiento agrario español (siglos xix y xx)", en El pozo de todos los males. Sobre el atraso en la agricultura española contemporánea Josep Pujol, et al. (España: Editorial Crítica, 2001), 46. En la misma línea de pensamiento, véase, del mismo autor "Crecimiento agrario y sostenibilidad de la agricultura española de los siglos xviii y xix", en Sombras del progreso. Las huellas de la historia agraria, Ramon Garrabou, (España: Editorial Crítica, 2010), 321-352; Gloria I. Guzmán Casado y Manuel González de Molina, "Sobre las posibilidades de crecimiento agrario en los siglos xviii, xix y xx. Un estudio de caso desde la perspectiva energética", Historia Agraria, No. 40, (2006): 437-470; Manuel González de Molina y Víctor M. Toledo, Metabolismos, naturaleza e historia. Hacia una teoría de las transformaciones socioecológicas (Barcelona: Editorial Icaria, 2011).

$4 \quad$ Enric Tello, "Un vínculo perdido: energía y uso del territorio en la transformación histórica de los paisajes agrarios mediterráneos", en Sombras del progreso. Las huellas de la historia agraria, Ramon Garrabou, (España: Editorial Crítica, 2010), 367. 
El propósito de este trabajo es analizar la interacción entre recursos naturales, desarrollo o metabolismo social y las consecuencias resultantes de esa relación manifiestas en la alteración y degradación de los sistemas ecológicos y en la conflictividad de las relaciones sociales. Privilegiamos para ello el valle de Puebla-Tlaxcala, localizado en la meseta central de México, y la etapa correspondiente al gobierno virreinal. La hipótesis que orienta la investigación es que la proyección de la ciudad de Puebla, la segunda en importancia de la Nueva España, después de la de México, y en la que se dio la conformación de una de las economías regionales más decisivas e influyentes durante el virreinato, estuvo basada en el consumo energético de los recursos naturales articulados y prodigados desde los volcanes y cordilleras que dominan imponentes los entornos urbanos y agrarios de este amplio y productivo valle: el Popocatepetl y el Iztaccihuatl, y de manera particular, La Malinche, La Malintzin o La Matlalcuéyetl, elevación que privilegiamos para este estudio.

En otras palabras, la realización de los procesos metabólicos sociales como fueron los urbanos, que marcaron de manera decisiva la relevancia e influencia alcanzada por la ciudad de Puebla, estuvo fundamentada en la transacción de flujos de energía y materiales provenientes de los ecosistemas agrarios articulados en torno al volcán.

El bosque particularmente, proporcionó uno de los recursos elementales para ese metabolismo como fue el de la madera, que ocupó una centralidad tanto como material para construcción o de «infraestructura» pero también como «energético» en la forma de carbón o de leña; funcionalidades que fueron decisivas para la significación alcanzada por la ciudad de la Puebla de los Ángeles pero que impactaron en la alteración y descomposición del ecosistema articulado en torno al volcán. Los flujos energéticos y de materiales, intensificados por los procesos metabólicos industriales que se impusieron durante el siglo XIX ${ }^{5}$, configuraron así una tendencia secular

5 José Juan Juárez Flores, “Besieged Forests at Century's End: Industry, Speculation, and Dispossession in Tlaxcala's La Malintzin Woodlands, 1860-1910", en A Land Between Waters: Environmental Histories of Modern México (ed.), Christopher A. Boyer (Arizona: The University of Arizona Press, 2012), 100-123, y "Alumbrado público en Puebla y Tlaxcala y deterioro ambiental en los bosques de La Malintzi, 1820-1870", Historia Crítica. Revista del Departamento de Historia de la Facultad de Ciencias Sociales de la Universidad de los Andes, Bogotá, Colombia, No. 30, Dossier: (2005): 13-38. 
hacia la degradación e insustentabilidad, que es la que afecta actualmente a la zona.

En efecto, el volcán La Malintzin o La Malinche, con sus 4.460 metros de altitud sobre el nivel del mar, la quinta elevación del país, ha sido de importancia vital para la región de Puebla-Tlaxcala. Su configuración abiótica -el agua, el suelo- y biótica -las plantas, los animales- la han constituido desde siempre en un sistema ecológico elemental de aprovisionamiento de recursos forestales e hídricos. Sin embargo, la importancia de esta función se ha visto fracturada con la destrucción incesante de la cubierta forestal a lo largo de diferentes procesos históricos o, en otras palabras, con la imposición de sucesivos metabolismos que han implicado la acumulación de diferentes intensidades de extracción de flujos de energía y materiales, impactando así en su degradación.

Los bosques constituyen uno de los ecosistemas más complejos que articulan y proveen un delicado equilibrio ambiental. Posibilitan la recarga de los mantos freáticos -lo que permite la disponibilidad del recurso hídrico-, contienen y dispersan la humedad, previenen la erosión, protegen la calidad de los suelos, capturan carbono y sirven de hábitat para miles de especies de la flora y la fauna. La deforestación, en consecuencia, es un problema con fuertes impactos económicos y sociales pero también ecológicos que ha llevado a la alteración de las condiciones ambientales que hacen posible la existencia de las formas de vida.

La tala incesante, la destrucción de los renuevos, el uso indebido de los suelos para cultivo agrícola, la quema intencional de la vegetación con propósitos de pastoreo y la extracción irracional del zacatón que compacta la superficie, aunado a la presión impuesta por el crecimiento demográfico, los asentamientos industriales, la explotación desmedida de los bancos de arena dejada al descubierto por la tala y utilizada para la industria de la construcción, así como los conflictos sociales generados en torno a la explotación del bosque -que involucran a carboneros y leñeros de los pueblos locales así como a bandas de taladores ilegales o clandestinos- han impactado de manera brutal en la descomposición de la biodiversidad. Diversas evaluaciones advierten que de no ser revertido este deterioro, fundamentalmente el del bosque, las tragedias ecológicas se anuncian in- 
minentes como ha sucedido ya con la desaparición de una parte significativa de los recursos lacustres del estado de Tlaxcala ${ }^{6}$.

La identificación, entonces, desde una perspectiva de largo plazo, de las formas que ha asumido el metabolismo social con sus condiciones, logros o realizaciones pero también con sus costes o contradicciones manifiestas en la degradación ecológica territorial y en la forma de las relaciones sociales. Un análisis de la interacción metabólica entre naturaleza y sociedad para contribuir, desde la Historia, a esa propuesta, pertinente, que es la construcción de una «nueva ciencia» de la sustentabilidad.

El análisis del planteamiento está estructurado en tres momentos: en el primero destacamos las formas de los «flujos energéticos y materiales» que fueron fundamentales para el metabolismo urbano de la ciudad de Puebla; subrayamos así la importancia de la madera y su centralidad a partir de su funcionalidad como energético y como material de construcción o de infraestructura; en el segundo resaltamos la conflictividad social generada en torno a los aprovechamientos y beneficios establecidos sobre estos recursos; por último, en el tercero, esbozamos la manera en que se perfila una tendencia secular a la degradación del ecosistema o de la «matriz territorial» con la intensificación de su explotación y con los conflictos de intereses. La implicación del planteamiento es que los flujos energéticos, con la alteración y descomposición de la articulación de los ecosistemas, generan formas de insustentabilidad, no solo de naturaleza ambiental sino también social.

\section{1. "Si A MORAR EN INDIAS FUERES, QUE SEA DONDE LOS VOLCANES VIERES"}

Así aconsejaba un proverbio español a los emigrantes a las posesiones americanas. La consigna se aplicó en la fundación de la ciudad de la Puebla de los Ángeles el 16 de abril de 1531, en la que se establecerían españoles

6 Para una identificación de los procesos que han incidido a esta situación, véase José Juan Juárez Flores, "Agua, agricultura e industria: las transformaciones en el paisaje lacustre de Tlaxcala, 1850-1900", en La Revolución mexicana en la provincia. Problemas comunes, variantes locales, Juan Uvaldo Estrada Ramos, Elizabeth Jaime Espinosa, Jesús Barbosa Ramírez y José Juan Juárez Flores (coords.), (México: Universidad Autónoma de Tlaxcala, 2012). 
pobres y errantes. El emplazamiento espacial elegido se caracterizaba por la dotación profusa de recursos naturales, entre ellos, extensas áreas de tierras fértiles, abundantes espejos y escurrimientos de agua, dilatados y espesos bosques, además de materiales necesarios para la construcción: piedras, caleras y barro se encontraban al interior o en los límites de la ciudad; de los pueblos comarcanos se traía cantera oscura de los rumbos de Cholula; una excelente piedra negra de Calpan y el ónix de los cerros de Tecali ${ }^{7}$; en tanto, la madera se obtenía de las extensas zonas boscosas que circundaban al incipiente centro urbano. Condiciones que le permitieron a la Puebla alcanzar aquella opulencia tan destacada en los escritos de viajeros y cronistas del siglo XVI, como lo constata el testimonio de la admiración que ya causaba a finales de esa misma centuria:

"La cibdad de la Puebla de los Ángeles es pueblo de españoles, de mucha vecindad, y va cada día aumentándose y en crecimiento, porque dentro del mesmo pueblo se saca cuanta piedra es menester para los edificios y se hace abundancia de cal, la cual vale barata; la madera se trae de la sierra de Tlaxcalla, cuya falda llega casi a la mesma cibdad; hay por allí grandes y espaciosas dehesas y en ellas gran suma de ganado mayor, y así para el servicio de la cibdad y traerle provisión, hay infinidad de carretas de bueyes y de mulas".

Los «flujos de energía y materiales» se perfilaban, así, entre las condiciones que posibilitaban las transformaciones que alcazaba el espacio urbano, es decir, su metabolismo social. Entre ellos ocupaban un lugar relevante los bosques que por diferentes rumbos se dilataban con el preciado recurso natural que contenían, la madera. Esta desempeñó funcionalidades que fueron centrales para los procesos metabólicos urbanos, como fue la de infraestructura para el soporte de las grandes construcciones civiles y religiosas al lado de habitaciones sencillas o modestas.

\footnotetext{
7 George Kubler, Arquitectura mexicana del siglo XVI (México: Fondo de Cultura Económica, 1992), 168.

8 Antonio de Ciudad Real, Tratado curioso y docto de las grandezas de la Nueva España (México: UNAM, 1976), 85-86.
} 
En efecto, opulentas construcciones como eran los edificios civiles, iglesias y conventos, pasaron a dominar el espacio urbano. Hacia 1625 ya destacaban por su notoriedad "un convento grande de Santo Domingo, cuya comunidad es por lo menos de 50 o 60 religiosos; otro de franciscanos, otro de agustinos, otro de la Merced, otro de carmelitas descalzos, y una casa de jesuitas; habiendo además cuatro conventos de religiosas" . El significado que tenía la madera para la magnificencia y distinción que alcanzaba la ciudad, junto con el cariz confesional que la caracterizaba, justamente puede representarlo la figura "emblemática" del beato fray Sebastián de Aparicio, de la orden de San Francisco, "que se ocupaba en el acarreo de la leña y maderas de que necesitaba el convento"10.

La opulencia alcanzada en la arquitectura transformaba rápidamente la fisonomía de la ciudad, tornando el espacio urbano en un conglomerado de edificios que cada vez con mayor insistencia se esparcía. La intensidad de los flujos de materiales para la construcción y ocupación de habitaciones es indicativa del dinamismo desplegado por la población. De los 81 vecinos "fundadores de la ciudad", algunos de ellos solteros y sin considerar en esa relación a las mujeres de los casados ${ }^{11}$, hacia 1556 ya se le estimaba una población de 600 habitantes; hacia 1568 se consideraba que había en ella cerca de mil españoles, "además de un gran número de indios"12. Hacia 1625 el fraile dominico inglés Thomas Gage estimaba el tamaño de la población en diez mil habitantes ${ }^{13}$. Hacia la década de 1790 la dimensión demográfica ya alcanzaba 57 mil habitantes; en contraste, la ciudad de Tlaxcala contaba solo con tres mil trescientos. La ciudad de Puebla se proyectó, así, como un influyente y dominante espacio articulador regional, a

9 Thomas Gage, Nuevo reconocimiento de las Indias Occidentales (México: conaculta, 1994), 90-91.

10 Miguel de Alcalá y Mendiola, Descripción en bosquejo de la imperial cesárea muy noble y muy leal ciudad de Puebla de los Ángeles (Puebla: Benemérita Universidad Autónoma de Puebla, 1997), 47.

11 Véase Eva Robles Galindo, "Las mujeres en el proceso de fundación de la Puebla de los Ángeles", en La presencia femenina en la Puebla novohispana. María Aurelia Hernández Yahuitl, et al., Siglos XVI y XVII, (Puebla: Ayuntamiento del Municipio de Puebla, 1999).

12 Joaquín García Icazbalceta (comp.), Relaciones de varios viajeros ingleses en la ciudad de México y otros lugares de la Nueva España. Siglo xvi (Madrid: Ediciones José Porrúa Turanzas, 1963), 27, 35.

18413 Ahí mismo señalaba: "Notamos su opulencia y sus riquezas, no solamente por la actividad de su comercio, sino por el gran número de conventos de frailes y de monjas, que se han fundado y que se mantienen en ella. El aire que se respira es bueno, y su pureza atrae todos los días multitud de gentes de todas partes que fijan allí su domicilio". Thomas Gage, Nuevo reconocimiento... 91. 
cuyos influjos quedó sometida la ciudad india de Tlaxcala junto con otros pueblos también de indios.

Junto con la de infraestructura, la madera desempeñó una funcionalidad energética en la forma de leña y de carbón vegetal, fundamental para actividades elementales y las de transformación. Para las sociedades agrarias, las posibilidades de «crecimiento», de su «metabolismo», estaban en gran medida determinadas por la cantidad de esa "energía" disponible ${ }^{14}$. Los bosques constituían, por consiguiente, depósitos de energía elementales ${ }^{15}$. Así, además de la construcción, actividades que le dieron fama y prosperidad a Puebla tuvieron como condición indispensable el consumo energético de la madera: lo mismo carpinterías que panaderías, tocinerías, locerías, ladrilleras, herrerías, pailas, carbonerías o los baños de temazcal. Los hornos particularmente, fueron devoradores insaciables de este «combustible». Así lo testimoniaban o insinuaban los cronistas de la ciudad. En junio de 1550 se apuntaba que era inconcebible el "excesivo precio" que había alcanzado la venta de la cal, no obstante "que la leña está muy cerca de los hornos" $"$.

Lo mismo con la "fábrica de cristales” que causaba admiración hacia 1625, "cosa tanto más rara cuanto que es la única de su clase que se ve en todo el país"17. O las panaderías, "que para la fábrica de los bizcochos" el carbón les era "el sustento más necesario"

14 Manuel González de Molina, "Condicionamientos ambientales del crecimiento agrario español (siglos XIX y xx)" El pozo de todos los males. Sobre el atraso en la agricultura española contemporánea Josep Puyol, et al., (España: Editorial Crítica, 2001.) Hasta la Revolución industrial, las plantas y los animales constituyeron las principales fuentes para la obtención de energía, véase el trabajo clásico de Carlo M. Cipolla, Historia económica de la población mundial (España: Editorial Crítica, 1983).

15 El reconocimiento de la importancia de las bases energéticas en el desarrollo y transformación de los procesos metabólicos sociales, ha llevado a diferenciar dos grandes tipos de sociedades en función de su fuente de energía predominante: sociedades de base energética solar o de economía orgánica y sociedades de base energética fósil o de economía inorgánica. Las sociedades de economía orgánica eran esencialmente sociedades agrarias, no solo porque su economía tradicional estaba limitada por la productividad de la tierra sino también porque el aprovisionamiento energético lo obtenían de las plantas en las que había quedado fijada la energía solar a partir de procesos fotosintéticos. Véase E. A. Wrigley, Cambio, continuidad y azar. Carácter de la Revolución industrial inglesa (Barcelona: Editorial Crítica, 1993).

16 Ordenanzas del 6 de junio de 1550, Archivo del Ayuntamiento de Puebla, (AAP), Vol. 2/ ff. 19v-20f.

17 “[...] se mira la Puebla como la segunda de México", Thomas Gage, Nuevo reconocimiento...92.

18 AAP; Cabildos, Vol. 18/ f. 79vta. 
laba que si "se han levantado templos suntuosos, grandes casas y edificios de admirable fábrica y arquerías [ha sido] por tener grande abundancia de pedreras de hacer cal, que se beneficia en muchos hornos, continuamente abasteciendo las fábricas de la ciudad y otras de más de veinte leguas en su contorno"19. A mediados de esa centuria, Francisco de Ajofrín daba testimonio de las implicaciones del energético en las realizaciones alcanzadas por la ciudad:

"Las fábricas en que se emplean los vecinos (tenidos por los más hábiles e ingeniosos de toda esta Nueva España, y con razón) son los delicados tejidos de lana, algodón de la China; hermosa, delicada y limpia loza, o barro aún más fino que el de Talavera; cristal y vidrio; todo género de armas finas y de fuego, que corren de gran fama en todo el reino por su delicado temple y primorosa hechura. Pero sobre todas estas fábricas, la más rica [sic], pingüe y opulenta es la del jabón, pues se surte de aquí casi todo el Reino" 20 .

Pero no solo en la realización de las funciones urbanas, en las formas que asume el "crecimiento" de la ciudad, sino también en sus regocijos, esparcimientos y aflicciones, el recurso natural bosque ocupó un lugar primordial. Las celebraciones de los santos patrones, los recibimientos de virreyes y otras formas de relajamiento social eran ocasiones en que también se consumían cantidades considerables de este recurso. En septiembre de 1601, para las celebraciones del arcángel san Miguel, santo patrono de la ciudad, además de las cámaras y cohetes que se quemaron en la víspera, se compraron seis carretadas de leña de ocote para las hogueras o iluminaciones que se hicieron frente a las casas del cabildo ${ }^{21}$. En octubre de 1624, entre los preparativos que se disponían para el recibimiento del virrey, se acordaba que a determinados trechos fueran colocados "librillos de brea

19 Alcalá y Mendiola, 53.

20 Francisco de Ajofrín, Diario de viaje a la América Septentrional en el siglo xviII, en, Puebla de los Ángeles. Industria y sociedad de una ciudad mexicana, 1700-1850, Guy P. C. Thomson (México: BUAP/Universidad Iberoamericana/Secretaría de Cultura de Puebla/Instituto Mora, 2002), 72. 22 de septiembre de 1601, AAP, Cabildos, Vol. 13. 
y ocote" para que en la noche se prendieran y ardieran, "de manera que el fuego dure y la plaza esté clara"22.

El sábado nueve y el domino diez de abril de 1701, fueron encendidas "luminarias, candelas y hachas" en el casco y barrios de la ciudad, con motivo de las honras fúnebres por la muerte del rey Felipe $v^{23}$. A finales de julio de 1722, para los festejos por el casamiento del príncipe, se quemaron 24 cargas de leña en las "luminarias" que se hicieron durante tres noches ${ }^{24}$. Un caso más: en 1746, con motivo de las celebraciones que durante diez días se hicieron en el recibimiento del virrey don Juan Francisco Güemes y Orcasitas, se gastaron 18 cargas de leña de encino para las luminarias de tres noches, catorce más para la cocina y otros tantos de carbón y leña que se utilizaron para "el tueste de diez arrobas de cacao" 25 . ¿Cuántos de estos eventos eran recurrentes en una ciudad de cariz noble y devocional? La implicación, desde luego es, ¿cuánta madera era consumida en las diferentes manifestaciones de su dignificación, además de la que se empleaba en su construcción y prolongación?

Hacia el siglo XVII ya era ingente el consumo de madera que había alcanzado la ciudad de Puebla, como lo constata la decisión de arreglar u ordenar el abasto que se hacía de este efecto. En enero de 1681, don Antonio de Olivares Villarroel, como procurador mayor, proponía "que para la buena expedición de los géneros que se traen a vender a esta ciudad como son carbón, leña, vigas y otras cosas de madera", se designarán los lugares en los que se vendieran estos efectos. Se acordó, así, que en la plazuela de san Francisco, que también llamaban de Peña, parara y se vendiera toda la leña que llegara de la sierra de Tlaxcala: vigas, tablas, cuartones, tejamanil, así como "toda la demás madera para que de allí se provean los vecinos"; que el carbón, también de la Matlalcuéyetl, se condujera a la plazuela de san Luis y que a la de la Compañía de Jesús se llevara "el carbón que bajare del pueblo de Amozoque"; a la del Carmen, el que "trujieren del pueblo de Cuauhtinchan, Aguacates y de los ranchos" y a la plazuela de san Agustín

225 de octubre de 1624, AAP, Cabildos, Vol. 16.

2327 de marzo de 1701, AAP, Cabildos, Vol. 34/f. 615vta.

24 AAP, Cuentas, Vol. 2.

25 AAP, Cuentas, Vol. 11. 
toda la madera que se trajera de los ranchos de por ese rumbo, como eran: tablas, cuartones, cajas, sillas, bancas "y la demás"26.

Vigas, morillos, tablas, cuartones, tejamaniles, polines, cargas de leña de encino "para el horno de la cocina" o de ocote para las "luminarias" de las noches de celebración, eran comercializados o intercambiados en cantidades considerables todos los días. Las actividades cotidianas demandaban y eran consumidoras de grandes cantidades de estos efectos; los diferentes oficios hacían uso de distintas cantidades y calidades. Para la construcción y la carpintería, las calidades más apreciadas eran el fresno y el ayacahuite; del jalocote y oyamel se obtenían viguetas, morillos, latas, tablas de techar, tablas de tripa, tablas judías; la madera de encino también se utilizaba para la construcción de carruajes y carros, y de la de ocote se sacaba el tejamanil que se utilizaba "para los suelos de las viviendas" y "para los techos" 27.

Si atendemos a lo que registra una referencia tardía, la transacción o trato de estos efectos era "por piezas, y el precio se arregla por las dimensiones que tienen, esto es, según su más o menos largo, ancho y grueso; las que no tienen estas circunstancias, se extienden por docenas, cientos, miles, etc., como lata, tejamanil, etc."28.

Las correcciones o los castigos a las transgresiones sociales precisaban asimismo de la madera. En 1785 Francisco Cisneros, maestro carpintero vecino de la ciudad de Tlaxcala, entregaba una relación de los gastos causados en la horca que hizo y puso en la plaza pública de esa ciudad para la ejecución de la pena de muerte ordenada por la real sala del crimen del reino en contra de José Mariano Sandoval, y consistieron en doce vigas de más de ocho varas de largo; once vigas de marca para pitipiés y puntales; 20 tablas para los escalones de las dos escaleras, además de mecates, brea, ocotes, leña y la paga del maestro albañil y peones ${ }^{29}$.

AAP, Cabildos, Vol. 30 /ff. 120v.-121f.

18827 Para este señalamiento nos hemos basado en Eugenio Maillefert, Directorio del comercio del Imperio Mexicano, (México: Instituto Mora, 1992), 118 (Colección Facsímiles).

28 Eugenio Maillefert,... Directorio del comercio, 135.

29 Archivo General de la Nación (AGN), Propios y Arbitrios, Vol. 8, 1785. 
Los productos derivados de la madera como eran la brea o resina también eran precisados en los usos cotidianos: en septiembre de 1658 el cabildo poblano prohibía que se mezclara la resina de los ocotes en la elaboración de candelas o velas ${ }^{30}$; en mayo de 1795 , entre los gastos erogados "en un remiendo" que se le hizo al palacio en que se alojaba el intendente, fueron registrados cuatro reales para la compra de hachas de brea que se aplicó en las antorchas con que se iluminaron los que entraron a desazolvar el "común" de la tropa.

De esta manera, ¿'es posible pensar en los «fulgores» que alcanzó la ciudad de los Ángeles sin considerar las cantidades de ese «combustible» que precisaba y consumía en su funcionamiento o metabolismo y que la hicieron «irradiar»? Concretamente, ¿es posible hacerse una idea de la magnitud que alcanzaba el consumo de estos efectos?

En noviembre de 1696, fueron hospedadas y mantenidas por cuenta del erario municipal las 237 personas que integraban la comitiva que vino acompañando al virrey conde de Moctezuma en el recibimiento que le fue tributado en la ciudad de Puebla ${ }^{31}$. El séquito lo componían el virrey, su esposa, un hijo y cuatro señoritas; el conde de San Román y su sobrino; 20 damas, diez dueñas, una ama, 30 pajes de gentiles hombres, un caballerizo mayordomo que aunque no se hospedó en el palacio sí comía en él, su esposa, a la que se llevaba su ración todos los días; el médico, su mujer y una hija; dos criados y una ama; 80 pajes españoles, 12 reposteros, 16 cocineros y ayudas de cocina, 12 guardarropas, cuatro bordadores, seis sastres, un cirujano, cuatro silleros de mano y 25 pajes de pajes de su excelencia.

Tan distinguido honor se prolongó durante 36 días, convengamos un mes, durante los cuales, la ciudad hizo varios gastos que consistieron en chocolate, azúcar ("en la cocina, repostería y aguas"), canela (que "se gastó en las aguas, repostería y cocina"), ropa para las mesas, tazas, paños de manos, dulces de monjas, colaciones, pan ("para los señores, señoritos y damas" se compró de la casa de don Juan Ortiz "y para las demás familias" se compró de la plaza), fruta de horno, especias; carnes que consistieron en

30 AAP, Cabildos, Sesión del 16 de septiembre de 1658. Vol. 24.

31 AAP, Cabildos, Vol. 34/ff. 326vta.- 327vta. 
306 carneros (de ocho a nueve carneros diarios - "sin escalfar viernes ni sábado porque en estos días era el gasto de ellos uno mismo porque toda la familia estaba en forma y comían carne dichos días"-), 18 terneras, 100 cabritos, dos venados, 40 lechoncillos, 24 pichones, 80 lenguas de toro, criadillas, sesos y tuétano de vaca; 23 de jamón, 22 libras de chorizo, doce libras de longaniza, 37 lomos frescos, 3.400 gallinas (más de 90 gallinas diarias), 700 pollos y pollas (20 pollos y pollas todos los días en el plato de aves), 100 capones, 45 gallinas de la tierra, o sea, guajolotes; de pescado se compraron 150 empanados de bobo, 16 de bobo de atarraya, 4 de ostión, 6 de camarón, 7 de pescado róbalo, 50 pargos, seis bobos de limón, tres bobos asados, además de vinos, palilleras, jarros, losa, velas y verdura ${ }^{32}$.

De acuerdo con el mismo registro, durante esos 36 días "se compraron y gastaron" 247 cargas de carbón para la cocina junto con doce cargas de leña de encino también para el "horno de la cocina", esto es, se advierte de manera clara el predominio del consumo de carbón sobre el de la leña de encino la que, después de quemada, dejaba como residuo precisamente el carbón, ambos efectos imprescindibles para la cocción o preparación de los alimentos; además de 143 cargas de leña de ocote para las "luminarias" de las cuatro noches de fiesta y cinco cargas también de ocote para las candeladas o fogatas; se gastó asimismo en candelas de sebo o velas para la iluminación de los espacios interiores como fueron el tinelo, la despensa, cocina, repostería, sala de cabildo, escalera, cochera, caballerizas, cuerpo de guardia, cuarto del médico, diputación y sala de dueñas ${ }^{33}$. Si convenimos también en 240 las personas que consumieron en un mes particularmente esas 247 cargas de carbón junto con las doce cargas de leña en la cocina, tenemos que cada persona habría consumido poco más de una carga de carbón al día por tan solo 0,05 de carga de leña.

Otra referencia, esta de un cronista de la ciudad, señalaba que hacia 1746 se encontraban repartidas en la traza urbana "hasta el número de tres mil quinientas noventa y cinco casas (se entiende las principales [...] no entrando en este número las casillas o chozas de los Naturales, con advertencia que son pocas las casas grandes que no están hechas hoy de vecin-

33 AAP, Cabildos, Vol. 34 / ff. 335vta. 
dad)" "Con una población estimada en 50.366 habitantes hacia este año, ¿cuánto carbón o leña se consumía en los fogones o tlecuiles domésticos ${ }^{35}$, tanto de las casas "principales" como de las humildes "casillas o chozas de los naturales"?, ¿cuánta más en las unidades productivas o «industriales», particularmente las de transformación?

Una referencia que desborda un poco la delimitación temporal que aquí nos ocupa, señala que el consumo anual de carbón en la ciudad de Puebla entre 1837-1842, con una población que promediaba poco más de 40 mil habitantes, era de unas 83 mil cargas, "con tendencia a crecer" ${ }^{36}$. Esto es, casi siete mil cargas mensuales, poco más de 230 cargas cada día, equivalentes a 37.950 kilogramos $^{37}$, ¿entre 35 y 40 toneladas? de consumo de carbón vegetal diario para una población, reiteramos, de poco más de 40 mil habitantes.

¿En qué consistía o cómo se componía la carga de leña y de carbón? De acuerdo con lo que prevenía una ordenanza de $1668^{38}$, la dimensión y precio de estos productos se ajustaba de la siguiente manera:

- 60 rajas de ocote, de las que suelen vender los indios, por un real.

- 25 rajas de encina de a vara, que llaman de canoa, por otro real.

- Una carga de leña de pino de tres carguillas, de las que traen los indios, que cada carga tuviere cincuenta leños de a tres cargas [¿نaras?] de largo, por dos reales.

34 Fray Juan Villa Sánchez, Puebla sagrada y profana. Informe dado a su muy ilustre ayuntamiento el año de 1746 (facsímil) (Puebla: Benemérita Universidad Autónoma de Puebla, 1997), 21.

35 Tlecuil: "Hogar u hornilla formado con tres piedras sobre las que se coloca el comal para las tortillas, o la olla para guisar la comida; en el espacio que dejan las piedras se acomoda la leña o el carbón", José Joaquín Fernández de Lizardi, El periquillo sarniento (México: Editorial Porrúa, 2000), 467 (Sepan cuántos, 1).

36 Francisco Téllez Guerreo, De reales y granos. Las finanzas y el basto de la Puebla de los Ángeles (Puebla: Universidad Autónoma de Puebla, 1986), 84.

37 Si convenimos en que una carga se componía de tres costales trilleros, uno a cada lado de la bestia y el otro sobre el lomo, con capacidad cada uno de entre 52 y 55 kilogramos de carbón de encino, el peso total de la carga se componía de aproximadamente 165 kilogramos. "El carbón bueno es el de encino, a diferencia del de ocote que es bofo". Esto, de acuerdo con los informes que nos han proporcionado carboneros longevos de algunos pueblos del entorno a La Malintzin.

38 Eusebio Ventura Beleña, Recopilación sumaria de todos los autos acordados de la Real Audiencia y Sala del Crimen de esta Nueva España [1787] en Entre el lujo y la subsistencia. Mercado, abastecimiento y precios de la carne en la ciudad de México, 1750-1812 Enriqueta Quiroz, (México: El Colegio de México/Instituto Mora, 2005), 253. 
- Una carga de las de encina que tuviere ochenta rajas de a vara cada una, por tres reales.

- Una carga de carbón de tres costales cada tercio, de una vara y cuarta de largo, cada uno [¿una?] por seis reales.

- Además de los incontables "tercios" que en sus espaldas traían los indios al mercado de la ciudad.

Se observan variaciones en el contenido y forma de la carga, esto es, en la cantidad, tamaño y grosor de las rajas de leña, lo que estaba en correspondencia con los diferentes usos que precisaban igualmente distintas calidades de este combustible: no era la misma leña que se utilizaba "para el horno de la cocina", de encino como consignan los datos; para las "luminarias", de ocote que por su contenido de resina o trementina la hacían propicia para arder y generar una iluminación intensa; que la que consumían los hornos de las "industrias" como eran las salitrerías: en 1809 las dos que se localizaban en la provincia de Tlaxcala, una en la ciudad y la otra en Ixtacuixtla, consumían "leña de tres cuartas de largo el trozo y media vara de ancho el grueso a seis leños de estos por medio [real]" 39 . Había, entonces, diferentes consumos de leña, en intensidades igualmente incomparables pero siempre en constante e intermitente demanda.

Se percibe, entonces, el significado que tuvieron los «flujos de energía» para las realizaciones metabólicas que alcanzaría la Puebla de los Ángeles; entre ellos destacaban los que provenían del volcán La Malintzin o Matlalcuéyetl. Hacia 1746 se señalaba enfáticamente que:

"Los esquilmos y frutos que ha tributado la Sierra de Tlaxcala en todas edades y tiempos a la Puebla y otros lugares de carbón, quartones, leña, tablones, tablas, y otras maderas son indecibles por lo opulento que ha sido en su redondés y partes de árboles y encinas" $" 40$. 468/ Exp. 16.

40 Diego Antonio Bermúdez de Castro, Theatro angelopolitano o historia de la ciudad de Puebla (1746), (Puebla, 1985), 160 (fascímil). 
La centralidad que ocupaba el recurso forestal para los procesos metabólicos sociales como fueron la construcción civil y religiosa, la cocción y producción de alimentos, como materia prima para las actividades productivas y artesanales, como energético para los procesos «industriales» o de transformación y, desde luego, el consumo doméstico, acentuaron su creciente demanda junto con la definición y contradicción de intereses.

\section{LOS «FLUJOS DE ENERGÍA» Y LOS CONFLICTOS DE INTERESES}

Los flujos de energía que precisaba la ciudad, hicieron de la explotación y provisión de la madera actividades indispensables. Diariamente, junto con el trajinar de los hombres, la ciudad se veía atravesada por el ir y venir de jamelgos y jumentos que tiraban de las carretas que traían los preciados efectos madera -en su forma de vigas, tablas, morillos, polines, tejamaniles-, leña -de roble, de encino o de pino- y carbón.

Las modestas cargas de madera o de leña que en los inicios de la ciudad llegaban a lomo de indio, de burro o de caballo, bien pronto fueron insuficientes y relegadas por la que se introducía en carretas. En junio de 1550 se señalaba que uno de esos vehículos salía a las siete de la mañana por un camino "muy llano e sin riesgo" a traer la leña a los montes cercanos a la ciudad, de donde volvía cargada con ese efecto para llegar aproximadamente a las tres de la tarde de ese mismo día ${ }^{41}$. La leña se vendía por "carretada" o por "brazo" 42 . El señalamiento es significativo pues ciertamente puede sugerir las dimensiones que iba alcanzando la demanda o el consumo con el ensanchamiento del cuadro urbano y, junto con ello, el impacto acarreado sobre los bosques del entorno a la ciudad; pero también es indicativo de la configuración de los beneficios e intereses que acarreaba su comercialización: ¿quiénes compraban solo brazadas de leña?, ¿quiénes, por el contrario, la compraban por carretadas y para qué?, ¿para consumirla, en qué actividades?, ¿para acapararla y especular con ella, y obtener así algún beneficio?

41 AAP, Ordenanzas, Vol. 2/ ff. 20fte.-20vta.

42 Brazada si extendemos el sentido de la expresión para significar la cantidad de leños que pudiera contener el brazo arqueado y sujetados o abrazados por el otro brazo, AAP, 28 de noviembre de 1547 Cabildos, Vol. 5, f. 211f-211v, Vol. 6, 17 de diciembre de 1548/f. 3v. 
Como tratamos de sugerir o de demostrar a continuación, la fecha de 1550 es significativa pues acusa las disyuntivas o contradicciones que había acarreado la explotación y consumo de leña en la realización de los procesos urbanos: de una parte, su consumo incontenible e inconmensurable; de otra, el asedio y preocupación por el retroceso de los bosques inmediatos a la ciudad, esto es, la inquietud por el agotamiento de sus reservas "energéticas"; y, de otra más, la obtención de beneficios y creación de intereses en torno a la explotación y transacción de la madera ${ }^{43}$.

A mediados del siglo XVI estos fenómenos estaban estrechamente relacionados. La demanda en constante crecimiento de madera había ido formando y consolidando una de las manifestaciones recurrentes en el mercado de la ciudad de Puebla: el surgimiento y presencia de los regatones y la práctica de la regatonería, esto es, el acaparamiento y la especulación en las transacciones mercantiles de la madera. A pesar de las disposiciones que se habían vuelto recurrentes del cabildo para regularizar esta práctica, los beneficios e intereses generados de su comercialización se impusieron a esas contenciones.

Varios eran los síntomas que acusaban la agudización de este padecimiento que, desde luego, era en beneficio de quienes comercializaban la leña, particularmente de los "carreteros" o carretoneros, pero que impactaba en perjuicio del bien común. Así, a finales de noviembre de 1547, en consideración a que "por cuanto las carretadas de leña que se entran a vender a la plaza son muy pequeñas y angostas de que redunda gran daño a los vecinos e porque se evite", la ciudad ordenó que se pregonara "públicamente" "en la plaza pública, por voz de Alonso Rodríguez, pregonero público", la ordenanza de las carretas que prevenía "que ninguna carretada de leña se pueda vender por ningún precio si no tuviere [¿hecha la reja?] de una vara de ancho e hasta arriba e vara e media de alto e venga llena de leña, so pena que se haya por perdida la leña e se aplique la mitad para proveer [y] la otra mitad al denunciador" ${ }^{\prime 4}$.

43 Aspectos que por lo demás también fueron privativos de la minería como sistema económico-productivo.

44 AAP, Cabildos, Vol. 5, ff. 211f.-211v. El subrayado es mío. 
En diferentes ocasiones el cabildo había tratado de regularizar estas anomalías que impactaban, además, en los recursos forestales de la ciudad. Imparable como era la expansión física y poblacional del casco urbano, la demanda de madera se incrementaba con la misma intensidad. Como era de corresponder, los bosques de los montes comarcanos se veían sometidos cada vez con mayor insistencia al asedio y destrozo de leñadores y carretoneros. El gobierno de la ciudad trató de regular su explotación por medio de disposiciones u "ordenanzas" que promulgó en diferentes momentos. Sin embargo, ante la recurrencia con que se infringían las disposiciones, en octubre de 1546 nombraba a un "guarda para los montes, ejidos, términos y dehesas de la ciudad" 45 .

Las necesidades crecientes de madera, sin embargo, violentaban estas restricciones. Los beneficios de su comercialización habían hecho proliferar la presencia de leñadores y de fabricantes de carretas ávidos de abastecer de leña a la ciudad. El cabildo pretendió regularizar el asedio sobre los montes con la expedición de licencias para cortar árboles. Así, en noviembre de 1546 prevenía por medio de ordenanza, que ninguna persona, "en particular las que fabrican carretas”, podía cortar árboles de los ejidos, términos y montes de la ciudad sin la autorización correspondiente ${ }^{46}$. Consecuentemente, en el mismo mes de noviembre le fue permitido a Juan de Ortega "cortar veinte árboles para hacer veinte carretas"; a Juan López de la Rosa "cortar madera de pino en los términos de la ciudad para poder edificar molinos de aceña $a^{47}$, batanes y carretas", y a Pedro López de Fuentes, carretero, el "corte de madera suficiente para [construir] treinta carretas" $"$.

Irónicamente, el remedio prevenido solo tendía a agravar y a hacer más evidente la magnitud que adquiría el malestar. Con los tres permisos expedidos se autorizaba el corte de árboles suficientes para la construcción de más de 50 carretas; si consideramos que el acarreo de madera y leña era

\footnotetext{
45 AAP, Cabildos, Vol. 4, ff. 254vta.; Vol. 5, ff. 156vta., 157fte-157vta.

46 AAP, Cabildos, Vol. 5, ff. 157vta.-158fte.

47 Molinos de agua, véase Alberto Carabarín Gracia, Agua y confort en la vida de la antigua Puebla (México: Benemérita Universidad Autónoma de Puebla, 2000), 122.

48 AAP, Cabildos, Vol. 5, ff. 160fte, 172fte, $173 \mathrm{fte}$.
} 
una de las prioridades, 50 de esos vehículos sugieren las dimensiones que iba adquiriendo el consumo de esos efectos que, desde luego, tendía a crecer y que implicaba el corte o destrozo de una cantidad también creciente de árboles.

Para un régimen con limitaciones en sus posibilidades no ya de acumular sino de conservar energía ${ }^{49}$, preciso le era buscar el equilibrio o una actitud "conservacionista" en la explotación de sus recursos, como era el bosque. Cuestión que no escapaba a los intereses de la ciudad y por supuesto, de la Corona. Por consiguiente, después de la Ordenanza de las carretas de 1547, emitida provisoriamente por el cabildo ${ }^{50}$, en 1548 “el presidente e oidores" expidieron una "ordenanza sobre los montes" 51 , seguramente para regular los excesos que contra los de la ciudad de Puebla se cometían. En ella se señalaba "que porque las personas que van a cortar leña o madera a los montes de esta ciudad cortan los árboles por el pie, por manera que si al [¿a lo uso?] dicho se diese lugar, por tiempo vendrá a que no tuviese montes esta dicha ciudad y sería en gran daño y perjuicio de ella", para prevenir esta situación indeseable, "ordenaron y mandaron":

"Que cualquier persona que fuere a cortar la dicha leña o madera en cada un árbol deje orca y pendón y no se pueda cortar el dicho árbol entero sino fuere para vigas y tablazón paella [palabra ilegible] de maderar casas, so pena que de que lo contrario hiciere

49 "Se comprende así que las sociedades de base orgánica fuesen sociedades fundadas en la escasez (Wrigley) dado que las posibilidades de acumular energía eran bastante limitadas", Manuel González de Molina, "Condicionamientos ambientales...", véase también Wriley, cambio, continuidad y....

50 Decimos provisoriamente porque, como señala Haring, "Desde el inicio de la colonización, a las autoridades en América la corona les permitió emitir ordenanzas de aplicación local, sujetas a una aprobación real última". Clarence H. Haring, El imperio español en América, trad. Adriana Sandoval (México: COnACulta/Alianza Editorial Mexicana, 1990), 159. Es probable que la falta de esta aprobación también hubiese impactado en la afectación de su patrimonio municipal, por lo que, ante el desafío que enfrentaba la ciudad en la disputa de sus intereses, faltos estos de precisión o mejor dicho, de reconocimiento, en enero dos de 1548 el cabildo se autorizaba o hacía "merced" de todos los manantiales de agua, ríos, fuentes, ejidos, sitios de molinos y batanes a los propios de la ciudad. Sesión del 2 de enero de 1548 AAP, Cabildos, Vol. 5,/ ff. 224fte. Los montes y los bosques quedaban considerados en las tierras que con la calidad de ejidos formaban parte, junto con los pastos o dehesas, del patrimonio concejil, esto es, de los «bienes de propio» o «propios» de la ciudad.

51 AAP, Ordenanzas, Vol. 2/f. 6. 
caiga e incurra por cada una vez en pena de tres pesos de oro de minas aplicados según dicho es" ${ }^{52}$.

La ordenanza, como otras más, aunque "hechas por el presidente e oidores", está fechada en Alcalá de Henares a los 13 días del mes de febrero de 1548. Esto nos lleva a considerar que, lo mismo que las ordenanzas de otros gremios u oficios ${ }^{53}$, las fórmulas de su contenido fueron tomadas de las legislaciones existentes para los reinos allá en la metrópoli, como el de Alcalá de Henares en este caso, lo que sugiere el apremio o preocupación por las dimensiones que había alcanzado la explotación de los bosques en la Nueva España ${ }^{54}$ y que Antonio de Mendoza, como se insinúa del análisis exploratorio de Andrés Lira, intentó enfrentar con la adaptación de algunas fórmulas de esas ordenanzas, como las promulgadas para la conservación de los montes.

Efectivamente, aunque el virrey señalaba hacia 1550 que «Están hechas Ordenanzas para la conservación de los montes», refiere Andrés Lira que "No sabemos, pues no la hemos localizado, si hubo una [ordenanza] para Nueva España. La que se cita o se emplea años después es la Ordenanza de los Reyes Católicos de 1496; en la que se dispone que los montes sean comunes para que los vecinos puedan aprovecharse de ellos, pero cortando las ramas y no los árboles por el pie, dejando horca y pendón para que

52 AAP, Ordenanzas, Vol. 2/f. 6. De acuerdo con un referente de la época, se define "orca y pendón” de la siguiente manera: "que es dexar una buena rama acia un lado en angulo recto con el tronco, y otra derecha, ó en angulo obtuso, para que tengan curbatones, genoles, ó barengas para Navios”. P. B. Villarreal de Berriz "Máquinas hidráulicas de molinos y herrerías y gobierno de los árboles y montes de Vizcaya (1736)". Edición facsímil del año 1793, en Arantza Gogeascoechea, "La Institución de los jueces de montes en Vizcaya. Siglos XVI-XvIII", en Boletín de la Real Sociedad Bascongada de los Amigos del País, 2001/2: 339-363.

53 Como fue el caso de los panaderos, véase Virginia García Acosta, Las panaderías, sus dueños y trabajadores. Ciudad de México, siglo xVIII (México: CIESAS, 1989) particularmente el capítulo tercero, $87-112$.

54 En 1550 el virrey Antonio de Mendoza señalaba en el punto 10 de la Relación que dejaba a su sucesor: "En muy pocos años ha sido gran cantidad de montes los que se han gastado, y teniendo consideración de esto, parece que antes ha de faltar la leña que los metales". En Andrés Lira, "Los bosques en el virreinato Apuntes sobre la visión política de un problema". En Relaciones. Estudios de Historia y Sociedad. Revista de El Colegio de Michoacán, No. 41 (1990): 118. Aunque con el señalamiento a "los metales" se alude ciertamente a la minería, la misma intensidad de consumo o quizás mayor todavía, se generaba en la realización de los procesos urbanos, como aquí tratamos de sugerir. 
puedan crecer y reproducirse" 55 . Esto es, los mismos términos y sentido que se advierten en la ordenanza del 13 de febrero de 1548 promulgada para la ciudad de Puebla, lo que nos hace deducir, efectivamente, que ante la situación inquietante fueron adaptadas algunas de esas reglamentaciones para prevenir la conservación de los montes.

La preocupación por la regulación en la explotación de los bosques, acusa la intensidad de la demanda y la magnitud que había alcanzado el consumo de madera en la Nueva España apenas hacia 1550, no solo en el beneficio de la minería, sino también en la realización de los procesos urbanos. Así lo sugiere la constante regulación, de igual forma hacia estos años, del cabildo de la ciudad de Puebla en la explotación, abasto y venta de los efectos de madera, leña y carretas. Pero también es delatora del beneficio que le acarreaba a sus expendedores, conseguido generalmente a partir de acciones transgresoras o ventajosas, que el cabildo pretendía limitar.

Así se denunciaba en la ciudad de Puebla, precisamente hacia el año de 1550, como especuladores o regatones, "españoles e indios" salían a los caminos a atajar y comprar los "bastimentos" y madera "que se traen por los naturales de esta comarca a vender a esta ciudad”. La práctica era en "perjuicio de esta república" pues, "lo tornan a revender y es causa de que lo vendan de subido precio e los esconden en sus casas los tales compradores". En el caso de la leña, quienes la vendían en la ciudad por carretadas "la suben en los precios de cada día", mismo abuso en el que incurrían los que hacían las carretas o carretoneros, no obstante "que los montes están cerca de esta ciudad de donde traen la tal leña" o "teniendo como tienen los montes de que cortan las maderas para ellas [las carretas] muy a la mano" 56 .

Así, después de las determinaciones preventivas que hasta entonces el cabildo había ejecutado, a comienzos de junio de 1550 promulgaba una serie de ordenanzas para corregir esas y otras irregularidades. La fecha es significativa, pues evidencia la potestad que la ciudad ya tenía o se le había conferido para emitir sus reglamentaciones y tomar sus decisiones, pero

55 Andrés Lira. "Los bosques en el virreinato..." 118-119.

56 AAP, Ordenanzas, Vol. 2/ff. 19fte.-20vta. 
también deja ver la consolidación que los especuladores habían logrado en el control de la venta de la madera. En aquella ocasión, "los magníficos señores justicia e regidores [...], platicando en las cosas tocantes a la buena gobernación de esta ciudad e república", respecto de los regatones "ordenaron e proveyeron":

"Que agora e de aquí adelante, ninguna persona español ni indio sea osado de salir ni salga a comprar fuera de esta ciudad dentro de sus términos, ningunas ni algunas cosas de bastimentos ni de maderas que los naturales de estas comarcas trajesen a vender a esta ciudad, sino que los dejen venir a lo vender libremente en las plazas y tianguis de ella para que allí lo puedan comprar e compren los vecinos e habitantes en ella" 57 .

Respecto de los vendedores de leña, señalaron la conveniencia de que se pusieran precios moderados a las carretadas de ese efecto, "de manera que los que la vendieren ganen en ella moderadamente y los compradores no padezcan"; por consiguiente, establecieron en cinco reales de plata la carretada de leña de roble o de encina y en cuatro reales la de pino, "siendo de dos varas de medir de alto e de ancho común [las dimensiones] de la tal carreta", esto es, media vara más de alto que la prevenida en la ordenanza de 1547. Se reglamentó asimismo, el precio y las dimensiones de las carretas. Ahí mismo se señalaban las penas o sanciones aplicadas a los transgresores, consistentes estas en la incautación o decomiso de los efectos o mercadería habidos de manera ilícita y su aplicación por terceras partes: una para los propios de la ciudad y las dos restantes para el denunciante ${ }^{58}$.

La madera y la leña ocupaban así, un lugar estratégico desde el que se definían posiciones e intereses encontrados. De una parte, los de la ciudad, con su afán por regular los excesos o abusos que impactaban en perjuicio de la "república" o del "bien común". Por la otra parte, los de los especuladores o regatones, que se habían ido apropiando de los beneficios obtenidos de su transacción mercantil. Aunque la madera y la leña estaban bajo 
la política regulatoria del cabildo en el abasto de los efectos que le eran vitales a la ciudad, el Concejo enfrentó la resistencia de los especuladores que se opusieron e impusieron a esas restricciones a partir de un manejo conveniente de la venta de esos efectos con la práctica de la especulación o del encarecimiento, esto es, de la regatonería.

Lejos de erradicarse, la práctica se fue posicionando hacia la segunda mitad del siglo XVI, de lo que son representativos algunos ejemplos. En diciembre de 1568 , se prevenía por medio de ordenanza que los carretoneros llevaran a vender leña a la plaza y que quienes tuvieran seis de esos carros hicieran dos viajes ${ }^{59}$. Igual sucedía en febrero de 1580, cuando se ordenó la obligación de que los carretoneros llevaran leña o bastimentos a la ciu$\mathrm{dad}^{60}$. Esto es, había desabasto, presumiblemente por encarecimiento de este efecto, atribuible quizás a una mayor demanda de su consumo por la temporada invernal que señalan esas fechas y no debido a la incidencia de algún apremio como pudiera ser alguna epidemia, que no se registra hacia estos años ${ }^{61}$.

Desde luego, la demanda era propicia para que se siguieran contraviniendo las ordenanzas. Las irregularidades o abusos en el tamaño o dimensión de la carga era una forma y ya en enero de 1575 el cabildo ordenaba que los carretoneros cumplieran las medidas establecidas de las carretas para la venta de leña ${ }^{62}$; en junio de 1584 volvía a insistir en el mismo asunto con la orden de que se pregonaran las dimensiones de las carretadas de leña, igual que con las de piedra, las que al perecer habían sido recientemente establecidas debido a la petición o queja del carpintero Alonso Gutiérrez, comisionado como estaba por el virrey para que vigilara y se cumplieran las ordenanzas respectivas ${ }^{63}$.

59 AAP, Cabildos, Vol. 10, 13 de diciembre de 1568, f. 54fte.

60 AAP, Cabildos, Vol. 11, 1 de febrero de 1580, f. 49fte.

61 Para una cronología de las epidemias en la Nueva España durante el siglo XVI, véase Lourdes Márquez Morfín, "La evolución cuantitativa de la población novohispana: siglos XVI, XVII Y XVIII", en El poblamiento de México. Una visión histórico-demográfica. Tomo II, El México Colonial (México: Secretaría de Gobernación/conapo, 1993), 56-57.

62 AAP, Cabildos, Vol. 10, 7 de enero de 1575, f. 148vta.

63 AAP, Cabildos, Vol. 11, 8 de junio de 1584, f. $162 \mathrm{fte}$. 
El corte de árboles sin licencia para hacer vigas en los montes, o el acaparamiento de leña junto con chiquihuites, petates, cántaros y otros bastimentos para revenderlos posteriormente ${ }^{64}$, se hicieron prácticas recurrentes. Aunque había un abasto relativamente constante y abundante de madera a la ciudad, una buena parte de ella, la de mejor calidad, era interceptada o atajada de manera cotidiana por los regatones. La disputa y el control de los intereses fincados sobre ella fueron motivo de conflictos recurrentes, de manera preponderante entre el gremio de carpinteros.

La agudización de los conflictos por la disputa y apropiación del recurso madera es la tendencia que se proyecta y se concreta en el siglo XVIII, que podemos atribuir a la presión impuesta por el crecimiento de la población, a los gravámenes a los que fueron sometidos algunos de sus efectos, y a la escasez que esos y otros factores acarrearon sobre el recurso.

En efecto, el crecimiento de la población que acusa la ciudad en el siglo XVIII implicó el incremento en la demanda de madera, si se quiere simplemente en la forma de «combustible», tanto para el consumo doméstico como para la "industria". La "coerción fiscal" impuesta por las Reformas Borbónicas afectó los productos maderables con la imposición del cobro de alcabala sobre algunos de ellos, como eran las vigas empleadas para la construcción. La presión así impuesta sobre la madera, tendieron a hacerla un producto escaso, atribuible no tanto a un agotamiento de los recursos forestales sino a la especulación de que la hicieron objeto los "españoles" que hacia la segunda mitad del XVIII habían desplazado a los indios en la producción, abasto y distribución de los productos maderables en el mercado urbano.

El metabolismo urbano intensificó, así, los «flujos energéticos». La desforestación de los sistemas ecológicos fue el impacto consecuente, tendencia que se configuraba en correspondencia con los logros o realizaciones que se alcanzaban. Los intereses encontrados por la disputa y apropiación de esos recursos generaron en conflictos sociales que incidieron, también, en la descomposición del entorno ambiental.

64 AAP, Cabildos, Vol. 11, 1 de febrero de 1580, f. 49fte.; Vol. 12, 22 de noviembre de 1594, f. 302vta. 


\section{Disputa de faldas, TAJOS DE HACHA Y HUMOS DE DisCORDIA: HA- CIA LAS FORMAS DE INSUSTENTABILIDAD}

Inversamente a esa imagen estereotipada que ve en la elaboración y venta de carbón, una actividad humilde y hasta poco redituable, propia de la condición del indio, lo que se destaca de manera contundente en la documentación de la época es la disputa constante entre indios y españoles por hacerse de los beneficios de la explotación y mercantilización de este producto del bosque. Disputa que desde el inicio buscó desplazar a los naturales de esos aprovechamientos en beneficio, primero, de los especuladores y luego de los hacendados que controlaban el mercado de los productos de madera. Circunstancia que corresponde a esa tendencia ascendente a controlar directamente la producción mercantil por un número cada vez mayor de empresas agrarias de propiedad europea, como se percibe ya desde la segunda mitad del siglo XVI para manifestarse plenamente en las primeras décadas del XVII ${ }^{65}$.

La disputa por los beneficios de la producción y transacción mercantil de los «flujos energéticos» constituye, efectivamente, una de sus manifestaciones, como se percibía ya a comienzos del siglo XVII con el carbón vegetal que se sacaba de los montes de la Matlalcuéyetl. Hacia esos años ya se había configurado una marcada pugna de intereses en torno a este producto. En 1602 se denunciaba de manera contundente que "la gente española de la ciudad de los Ángeles, Huamantla y otras partes", hacía "mucha desorden" en el monte "llamado Matlalcuyo", de donde sacaban tablas, vigas, tejamaniles, carbón y otras maderas ${ }^{66}$. Hacia 1617 se insistía en la misma situación, aseverando que junto con la elaboración de carbón, el corte de maderas, tablas, vigas y tejamaniles "cada día va en aumento" ${ }^{67}$.

La demarcación de linderos entre los pueblos de indios de las jurisdiccionales de las ciudades de Puebla y Tlaxcala que compartían la explotación

65 Carlos Sempat Assadourian, "La despoblación indígena en Perú y Nueva España durante el siglo XvI y la formación de la economía colonial”, en La formación de América Latina. La época colonial, introducción y selección de Manuel Miño Grijalva (México: El Colegio de México, 1992), 83 (Lecturas de Historia Mexicana).

66 AGN/Indios/Vol. 29, Exp. 234, ff. 184v-185f., Vol. 7, Exp. 154, ff. 75v.-76v.

67 AGN/Indios/Vol. 29, Exp. 234, ff. 185f.-186f, Vol. 7, Exp. 154, ff. 75v.-76v. 
del monte y que implicaban una forma de restricción a su acceso, agudizaron los conflictos como se había planteado ya desde comienzos del siglo xvi. El 18 de noviembre de 1549, el cabildo de la ciudad de Tlaxcala acordaba que se impidiera a los cholultecas "el saque de leña que se lleva a cabo aquí en nuestra tierra" 68 . En la ciudad de Puebla, a finales de julio de 1555, se denunciaba que muchos naturales de los pueblos de Cholula, Tlaxcala, Tepeaca, Cuauhtinchan, Tecali, Totimehuacan, Huejotzingo, Calpan "e otros pueblos de la comarca", entraban a los montes de la ciudad y causaban graves daños "porque cortan los árboles e llevan gran cantidad de maderas, leña e piedra e para esto es más lo que daña y se pierde que lo que de eso se aprovecha" ${ }^{\circ 9}$. Para agosto de 1594 los indios de Tlaxcala impedían ahora a la ciudad de Puebla que sacara maderas de la sierra ${ }^{70}$.

Los conflictos se prolongarían durante el siglo XVII y se agudizarían en el XVIII. En ellos se percibe la oposición de los indios de Tlaxcala a la invasión y el despojo de la posesión y disfrute que desde tiempos prehispánicos alegaban tener sobre los montes de la sierra. En agosto de 1637 la ciudad de Puebla denunciaba que unos indios de Tlaxcala y San Pablo Cuauhtotoatlan, junto con el teniente de San Felipe y Topoyango, habían subido al monte y aprehendido a los indios leñadores de esa ciudad, a los que amenazaron y quitaron las hachas y bestias que llevaban ${ }^{71}$. En febrero de 1638, otra vez manifestaba que nuevamente la justicia del pueblo de Santa Ana Chiautempan, de la jurisdicción de Tlaxcala, "[a]prehendió los indios, negros, mulatos y otras personas que estaban haciendo leña y carbón en el dicho monte y les quitó las cabalgaduras, hachas y herramientas con que hacían madera"72.

El trabajo diario en la explotación del monte y el trajín constante con la bajada de la madera, la leña o el carbón para conducirla al mercado urbano de Puebla, impactaron la superficie boscosa del monte, acarreándole así intensidades de descomposición ambiental. Varios indios de las diferentes

68 Actas de Cabildo de Tlaxcala, 1547-1567, México, Archivo General de la Nación/Instituto Tlaxcalteca de Cultura/ciesas, 1985, 269.

69 AAP, Cabildos, Vol. 7, f. 72.

70 AAP, Cabildos, Vol. 12, ff. 296v.

71 AAP, Cabildos, Vol. 18, ff. 254vta.-255fte.

72 AAP, Cabildos, Vol. 18, f. 300fte. 
comunidades de La Malintzin, “con el título de hacer leña y carbón”, prácticamente "viven en el monte" ". De día y de noche, entre la espesura del bosque, se hizo habitual el eco del tajo profundo de las hachas junto con el crujir de las ramas y troncos que eran derribados, además de las humaredas que desde diferentes rumbos se levantaban y que indicaban, desde luego, "estar haciendo carbón”.

Algunas referencias son ilustrativas al respecto. En enero de 1682, nueve indios de Tetlanohcan, por órdenes de su "amo", el hacendado don José Niño de Córdoba, subieron desde las ocho de la mañana "hasta dentro del monte" con catorce yuntas de bueyes para que bajaran unas vigas. En ello trabajaron todo el día y "habiéndolas cortado", las bajaron hasta un paraje conocido como "los ocotales", ahí mismo dentro del monte, donde "por ser tarde se quedaron allí a dormir y amarraron sus bueyes". A la mañana siguiente, al despertar, "se pusieron a uncir las yuntas" y el capitán de la cuadrilla junto con otro indio "se pusieron a rajar un palo de ocote para traer [leña] a sus casas" 74 .

El esquilmo nocturno del bosque se hizo habitual. En 1731, Miguel de Aparicio, indio de San Pablo del Monte, señalaba que de noche, en compañía de un hermano, sacaba leña y carbón del monte en lo que tenía "como tiene su comer con el acarreo de leña y carbón que saca de dicho monte y conduce a la Puebla" ${ }^{\prime 75}$. En septiembre de 1750 Juan de Dios, natural del pueblo de Canoa, declaraba que salía de su pueblo en compañía de Marcos de Santa María, su compadre, al monte de Huamantla “a hacer carbón; el jueves lo hicieron y el viernes se volvieron [regresaron] con una mula cargada"76.

Las denuncias en contra de los labradores, por el "desmonte" o "destrozo", se hicieron recurrentes; así se denunciaba en 1722, cuando a nombre de los caciques de la cabecera de Ocotelulco, de la provincia de Tlaxcala, se le previno a don Antonio Joseph Vidaurri se abstuviera de desmontar 
el monte ${ }^{77}$. El señalamiento es significativo pues acusa el desplazamiento que los labradores o españoles habían hecho de los indios en el control y explotación de este recurso, como lo constatan los robos de leña o «delincuencia forestal» en que incurrieron estos y que se acentúa hacia las postrimerías del gobierno virreinal.

Algunos casos son ilustrativos. En enero 13 de 1780, don Manuel Sáenz Cabezón, español, de 23 años de edad, de estado soltero y poseedor de la hacienda de labor llamada Nuestra Señora de Guadalupe Xaltelulco, localizada en el partido de San Pablo del Monte, señalaba que "con el motivo de conducir de su cuenta a la ciudad de Puebla la leña que produce el monte de mi hacienda, no permite el que los indios vecinos la corten como lo hacen en otras haciendas por el estipendio que dan, y así tiene ordenado a sus sirvientes no consientan el que haya arrendatarios del monte lo que ha estado ya verificándose de mucho tiempo a esta parte"; sin embargo, cierto día, al haber ido sus arrieros a ese paraje, vieron a ciertos indios que hacían sus cargas de leña de lo que le avisaron, y así, al bajar aquellos, hizo que les quitaran la leña junto con los cuatro burros y la yegua en que la conducían, además de que, "airado del burto que le habían hecho, les dio unos cuartazos"78.

A finales de octubre de 1794, José Félix Nieto de Almirón, vecino de la ciudad de Tlaxcala, señalaba que como encargado del rancho nombrado De Garzón, del que eran dueños los naturales del pueblo de Acuitlapilco y habían arrendado a don Rafael Mangino, dueño del molino de Topoyanco, se le previno que no permitiera que los naturales ni algún otro individuo cortaran leña ahí, pero que cierto sábado sorprendió a un natural que lo hacía y, al reprenderlo, aquel se le opuso, “y a [de] más de las malas razones con que me maltrató, me tiró una pedrada tan fuerte que me sumió algunas costillas". Entre otras satisfacciones, pedía que se les previniera "no entrometerse a la corta de leña" pues, de lo contrario, "queriendo excederse, podrá suceder una desgraciada muerte de una u otra parte"79.

77 AHET, Fondo Colonia, C52/722 Exp. / 22.

78 AHET, Fondo Colonia, Siglo XVIII, Sección Judicial Criminal, C35/780, Exp. 1.

79 [Que no corten leña en el rancho de Garzón], AHET, Fondo Colonia, Sección Siglo XVIII, C354/794, Exp. 9., ff. ss. 
En enero 16 de 1809, a pedimento de don Miguel Jerónimo Ramírez, dueño de la hacienda de San Sebastián Sumpango, se seguía una causa en un juzgado de la Acordada de la ciudad de Puebla, contra Manuel Trinidad, Juan Lucas, Pascual de San Sebastián “y uno que le nombran 'El Güero', por ladrones rateros de leña" 80 .

La explotación del monte junto con la disputa del recurso entre las dos partes, le acarreaba diferentes intensidades de descomposición ambiental. El corte mortal de las hachas junto a la quemazón de los hornos de carbón, consumían la prodigalidad de la Matlalcuéyetl. Por la parte de Puebla eran los mismos efectos. En marzo de 1823, el mayordomo de la hacienda de Santiago de los Leones, finca que era de los bienes de propios de la ciudad de Puebla y uno de cuyos linderos terminaba "hasta llegar muy cerca de la cima de La Malinche", señalaba que en ese lugar se hacía el corte de árboles para leña, de los que se sacaban quince cargas diarias a diferencia de los años anteriores cuando solamente se explotaban nueve. La versión de un indio, sin embargo, delató que de ahí se sacaban 40 cargas de leña diarias que en dos atajos de burros se llevaban a la ciudad de Puebla, lo que una comisión despachada por el cabildo constató de regreso de la finca por la tarde, al encontrar el primer atajo consistente "de 34 a 38 burros" y más adelante el otro "que no bajaba de 15 a 20", esto es, de 50 a 60 cargas diarias; uno de los arrieros señaló que, efectivamente, eran de la hacienda de Santiago ${ }^{81}$.

Desde luego, el administrador había mentido por conveniencia pues, como se señalaba en el informe de la comisión: "asombra[ba] ciertamente una extracción semejante" de leña, que había dejado a la finca "en grande manera aniquilada”, más aún cuando en los remates se exigía el cumplimiento de la ordenanza "que trata sobre el corte de maderas" y que prevenía que el locatario o arrendador dejara "orquilla y pendón" en el corte de los árboles. El cabildo ordenó así, en diciembre de 1823, que se suspendiera todo corte de leña y elaboración de carbón ${ }^{82}$.

80 AHET, Fondo Colonia, Sección Siglo XIX, Judicial-Criminal, C58/809, Exp. /30, f. s.

81 AAP, Expedientes, Vol. 41, ff. 154v-155f.

82 AAP, Expedientes, Vol. 41, ff. 156v.-158v. 
Diez años después, sin embargo, se constataba que no solo no se había detenido el esquilmo sino que este se había intensificado. En abril de 1834 se hizo una inspección o "vista de ojos" al monte de la hacienda ya conocida solo como de Santiago, ante la denuncia hecha al ayuntamiento de que aquel "se había arrasado completamente". En el informe entregado por el administrador, se señalaba que durante los años de 1829 a 1832, de los cortes de encino para leña se obtenían 68 cargas a la semana en contra de las 63 que se lograban en 1833, “además de las 20 o 30 [cargas] semanarias que asimismo se extraían" para el consumo de las pailas, esto es, una estimación moderada de 80 a 90 cargas de leña a la semana.

Del mismo corte de encino se producían a la semana ocho cargas de carbón entre 1829 y 1832 y catorce cargas, también a la semana, en 1833; "respecto del carbón de ocote", el arrendatario que tuvo la finca entre 1829 y 1832, vendía las hornadas en el mismo monte a tres reales cada una, las que producían "de seis a ocho cargas cada una”, en tanto que el arrendatario que la tuvo en 1833 vendía el carbón por cargas "que son cosa de 15 a 20 semanarias"; esto es, se había incrementado al doble la intensidad de la explotación pues, de acuerdo con lo que ahí mismo se señalaba, este último arrendatario exigía se le entregaran, esto es, que se explotaran "de 20 a 25 cargas semanarias", bien de leña o bien de carbón, mismas que, de acuerdo con el parecer del ayuntamiento, no se podían sacar "sino era arrasando el monte" 83 . Ahí mismo se señalaba "que era cierto se vendían las hornadas pero que no producían cada una arriba de cuatro a seis cargas de carbón".

Los lamentos exhalados con el estrépito del caer de los árboles y con el humo de sus calcinamientos marcaron de manera definitiva la fractura y el rompimiento de la articulación ambiental del paisaje. El retroceso de la cubierta forestal, amagada continuamente por el ensanchamiento habitacional, la erosión de los suelos, la desaparición de los vasos lacustres, la amenaza y en algunos casos la extinción de algunas especies de animales y plantas, los conflictos sociales por la disputa y apropiación de los recursos, han impactado en la articulación ambiental como ha sido en la fractura de 
la función de «vaso de condensación» y de regulador climático que juega esta inmensa estructura geológica. La alteración de los patrones de precipitación pluvial y el aumento en la temperatura promedio anual desde 1995 son unas de sus manifestaciones. Las formas de gestión de los recursos y de los flujos energéticos han tenido así, en la insustentabilidad, una de sus más caras consecuencias.

\section{Bibliografía}

\section{Fuentes de archivo}

AGN-Archivo General de la Nación.

AAP-Archivo del Ayuntamiento de Puebla.

AHET- Archivo Histórico del Estado de Tlaxcala, Caja/Año.

\section{Fuentes secundarias}

Bermúdez de Castro, Diego Antonio. Theatro angelopolitano o historia de la ciudad de Puebla (1746). Puebla, 1985.

Carabarín Gracia, Alberto. Agua y confort en la vida de la antigua Puebla. México: Benemérita Universidad Autónoma de Puebla, 2000.

Cipolla, Carlo M. Historia económica de la población mundial. España: Editorial Crítica, 1983.

De Ajofrín, Francisco. Diario de viaje a la América Septentrional en el siglo XVIII. En Puebla de los Ángeles. Industria y sociedad de una ciudad mexicana, 1700-1850.

De Alcalá y Mendiola, Miguel. Descripción en bosquejo de la imperial cesárea muy noble y muy leal ciudad de Puebla de los Ángeles. Puebla: Benemérita Universidad Autónoma de Puebla, 1997.

De Ciudad Real, Antonio. Tratado curioso y docto de las grandezas de la Nueva España. México: UNAM, 1976.

Fernández de Lizardi, José Joaquín. El periquillo sarmiento. México: Editorial Porrúa, 2000.

Fontana, Josep. "Los usos de la Historia: una reflexión sobre el agua". Vínculos de Historia. Revista del Departamento de Historia de la Universidad de Castilla-La Mancha No. 1 (2012).

Gage, Thomas. Nuevo reconocimiento de las Indias Occidentales. México: Conaculta, 1994. 
García Icazbalceta, Joaquín (comp.). Relaciones de varios viajeros ingleses en la ciudad de México y otros lugares de la Nueva España. Siglo XVI. Madrid: Ediciones José Porrúa Turanzas, 1963.

González de Molina, Manuel y Víctor M. Toledo. Metabolismos, naturaleza e historia. Hacia una teoría de las transformaciones socioecológicas. Barcelona: Editorial Icaria, 2011.

González de Molina, Manuel. "Crecimiento agrario y sostenibilidad de la agricultura española de los siglos XVIII y XIX”. En Sombras del progreso. Las huellas de la historia agraria, editado por Ramón Garrabou. España: Editorial Crítica, 2010.

González de Molina, Manuel y Gloria I. Guzmán Casado. Tras los pasos de la insustentabilidad. Agricultura y medioambiente en perspectiva histórica (S. XVIII-XX). España: Icaria Editorial, 2006.

Guzmán Casado, Gloria I. y Manuel González de Molina. "Sobre las posibilidades de crecimiento agrario en los siglos XVIII, XIX y Xx. Un estudio de caso desde la perspectiva energética", Historia Agraria No. 40 (2006): 437-470.

Juárez Flores, José Juan. "Besieged Forests at Century's End: Industry, Speculation, and Dispossession in Tlaxcala's La Malintzin Woodlands, 1860-1910”, En A Land Between Waters: Environmental Histories of Modern Mexico, editado por Christopher A. Boyer. The University of Arizona Press, 2012.

Juárez Flores, José Juan. "Agua, agricultura e industria: las transformaciones en el paisaje lacustre de Tlaxcala, 1850-1900”. En La Revolución mexicana en la provincia. Problemas comunes, variantes locales, (coords.) Juan Uvaldo Estrada Ramos, María Elizabeth Jaime Espinosa, Jesús Barbosa Ramírez y José Juan Juárez Flores. México: Universidad Autónoma de Tlaxcala, 2012.

Juárez Flores, José Juan. “Alumbrado público en Puebla y Tlaxcala y deterioro ambiental en los bosques de La Malintzi, 1820-1870”. Historia Crítica No. 30 (2005).

Kubler, George. Arquitectura mexicana del siglo XVI. México: Fondo de Cultura Económica, 1992.

Naredo, José Manuel. "Metabolismo económico y deterioro territorial, Tendencias y perspectivas a principios del siglo xxı". En El paisaje en perspectiva histórica. Formación y transformación del paisaje en el mundo mediterráneo, editado por Ramon Garrabou y José Manuel Naredo. España: Prensas Universitarias de Zaragoza e Institución Fernando el Católico, 2008, 391-412. 
Maillefert, Eugenio. Directorio del comercio del Imperio Mexicano. México: Instituto Mora, 1992.

Robles Galindo, Eva. "Las mujeres en el proceso de fundación de la Puebla de los Ángeles". En La presencia femenina en la Puebla novohispana Siglos XVI y XVII, editado por María Aurelia Hernández Yahuitl, et al. Puebla: Ayuntamiento del Municipio de Puebla, 1999. Sempat Assadourian, Carlos. "La despoblación indígena en Perú y Nueva España durante el siglo XVI y la formación de la economía colonial". En La formación de América Latina. La época colonial, introducción y selección de Manuel Miño Grijalva. México: El Colegio de México, 1992.

Téllez Guerreo, Francisco. De reales y granos. Las finanzas y el basto de la Puebla de los Ángeles. Puebla: Universidad Autónoma de Puebla, 1986.

Tello, Enric. "Un vínculo perdido: energía y uso del territorio en la transformación histórica de los paisajes agrarios mediterráneos". En Sombras del progreso. Las huellas de la historia agraria, editado por Ramon Garrabou. España: Editorial Crítica, 2010.

Tello, Enric. La historia cuenta: del crecimiento económico al desarrollo humano sostenible. Barcelona: Fundació Nous Horitzons/El Viejo Topo, 2005.

Ventura Beleña, Eusebio. Recopilación sumaria de todos los autos acordados de la Real Audiencia y Sala del Crimen de esta Nueva España [1787]. En Entre el lujo y la subsistencia. Mercado, abastecimiento y precios de la carne en la ciudad de México, 1750-1812, Enriqueta Quiroz. México: El Colegio de México/Instituto Mora, 2005.

Villa Sánchez, Fray Juan. Puebla sagrada y profana. Informe dado a su muy ilustre ayuntamiento el año de 1746 (facsímil). Puebla: Benemérita Universidad Autónoma de Puebla, 1997.

Wrigley, E. A. Cambio, continuidad y azar. Carácter de la Revolución industrial inglesa. Barcelona: Editorial Crítica, 1993.

Para citar este artículo: Juárez Flores, José Juan. "Entre fulgores de ángeles y máculas de tizne: energía, metabolismo y degradación ecológica en el Valle de Puebla-Tlaxcala, 1530-1820", Historia Caribe Vol. X No. 26 (Enero-Junio 2015): 175-210. DOI: http://dx.doi.org/10.15648/ hc. 26.2015 .7 